\title{
sala preta
}

\section{Teatro em comunidade na zona de contato: reinventando a práxis}

Community theater in the contact zone:

reinventing the práxis

Wellington de Oliveira

Wellington de Oliveira

Doutorando no Programa de Pós-Graduação em Educação Artística da Faculdade de Belas Artes da Universidade do Porto (FBAUP) em acordo de cotutela com o Programa de Pós-Graduação em Artes Cênicas da Universidade Federal do Estado do Rio de Janeiro (Unirio). Bolsista do Programa Conexão Cultura - Fundo de Apoio

à Cultura do Distrito Federal. Integrante do coletivo e grupo de pesquisa Terra em Cena (UnB). Professor da Secretaria de Educação do Distrito Federal (SEDF).

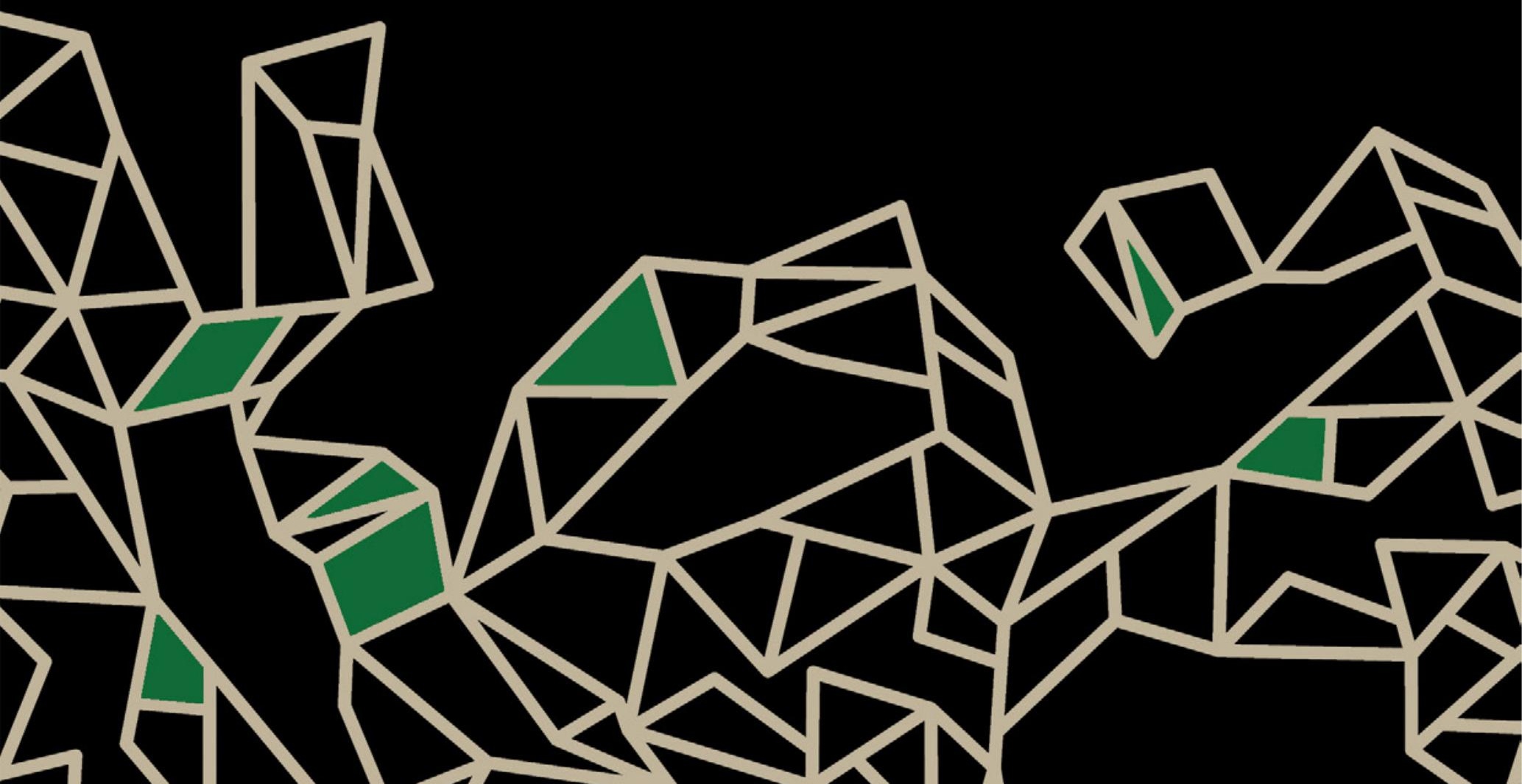




\section{Resumo}

O teatro em comunidade é uma prática que nos últimos anos passou a figurar nos debates acadêmicos e instituições culturais, atraindo artistas, professores e pesquisadores, entre outros profissionais interessados por práticas artísticas participativas. No interior de tais abordagens, este artigo pretende uma reflexão sobre os riscos dessas práticas se tornarem excludentes, na medida em que agregam discursos educacionais atravessados por uma forma de racionalidade que impossibilita a copresença e anula o "outro lado da linha" do que considera relevante. Sendo assim, reafirma a necessidade de atenção para o interior dos processos artísticos e para a forma como as práxis são construídas, situando o teatro em comunidade no espaço da "zona de contato" e a cena como uma presença dos sujeitos nesse espaço.

Palavras-chave: Teatro em comunidade, Emancipação, Zona de contato, Participação, Discursos educativos.

\section{Abstract}

Community theater is a practice that in recent years has come to appear in academic debates and cultural institutions, attracting artists, teachers, researchers, and a diverse range of other professionals interested in participatory artistic practices. Within such approaches, this article seeks to reflect on these practices the risk of excluding, since most discourses of education are pierced by a form of rationality that makes co-presence impossible and cancels the 'other side of the line' of what it considers relevant. Thus, it reaffirms the need for attention to the interior of the artistic processes and to the way praxis are constructed, placing community theater in the space of the 'contact zone' and the scene as a presence of the subjects in this space.

Keywords: Community theater, Emancipation, Contact zone, Participation, Educational discourses. 


\section{Sobre compreender as gramáticas das nossas práxis ${ }^{1}$}

Práticas artísticas pautadas por discursos comprometidos com o desenvolvimento sociocultural e proposições de integração e participação de comunidades norteiam cada vez mais o trabalho de artistas, organizações culturais e instituições públicas do mundo inteiro. No escopo de tais práticas integra-se o teatro em comunidade, um campo que nos últimos anos passou a ser incluído no âmbito da pesquisa em teatro-educação, entre outras iniciativas desenvolvidas nos territórios da educação não formal e das manifestações populares.

De acordo com Nogueira (2015), no contexto brasileiro a denominação "teatro em comunidade"2 não se refere a um tipo específico de teatro que é feito em comunidades, mas a diversas formas teatrais que acontecem nesses contextos, abrangendo variadas instâncias de interação entre artistas e comunidades. Assim, optamos por essa denominação por considerá-la mais abrangente e também por agregar as convergências de práticas semelhantes que ocorrem em várias partes do mundo, embora com definições diferentes. Em síntese, pretendemos uma reflexão sobre práticas pretensamente comprometidas com uma comunidade, com questões sociais e culturais que envolvem uma localidade ou grupo social específico, por meio do fazer teatral.

Para esta tarefa, torna-se necessário um olhar atento às narrativas que se inscrevem no campo do teatro em comunidade, constituindo suas epistemologias, teorias e políticas. No Brasil, por exemplo, enquanto área de pesquisa e extensão universitária, se institui a partir da necessidade de abrangência das práticas teatrais que ocorrem fora dos muros da escola, reconhecendo as particularidades e potencialidades de suas formas organizativas, porém com

1 A palavra práxis, em nossa proposta, surge no sentido marxista de relacionar a teoria e a prática. Para Marx, a "práxis revolucionária" é uma atividade teórico-prática em que tanto a teoria se modifica com a experiência prática quanto a prática se modifica com a teoria. No caso deste trabalho, construir uma práxis do teatro em comunidade está relacionado ao fato de investigar práticas, produzir reflexões e, de algum modo, contribuir para o desenvolvimento do campo.

2 Márcia Pompeo Nogueira (2009) destaca ainda três categorias do teatro em comunidade: teatro para comunidades - em que atores apresentam um teatro de mensagem sem conhecer a realidade da comunidade; teatro com comunidades - modelo em que atores investigam uma comunidade para criar um trabalho teatral; e o teatro por comunidades - que inclui as próprias pessoas da comunidade no processo de criação teatral. 
grande parte das reflexões ainda assentadas em padrões de racionalidade da educação e das práticas artísticas escolares, que se justificam a partir dos seus efeitos para o alcance de expectativas predeterminadas.

Nesses enquadramentos discursivos, o teatro em comunidade frequentemente é colocado no interior de um discurso essencialista sobre as artes "como elixires que podem ser injetados para transformar situações educacionais e garantir resultados particulares" (GAZTAMBIDE-FERNANDEZ, 2013, p. 214, tradução nossa). Assim, em meio às legitimas expectativas de um futuro diferente, de uma educação inclusiva e conectada com as práticas sociais, grande parte dessas práticas artísticas incorpora um discurso crítico, ressaltando diferenciais benéficos em relação às práticas artísticas e educativas tradicionais, como se fossem naturalmente inclusivas e não tivesse em seu bojo nenhum resquício das epistemologias dos modelos que criticam.

Seríamos realmente capazes de mudar algo sem nos incluirmos na realidade que desejamos transformar e sem refletir sobre as constituições das práticas que empreendemos? Aliás, esse é o mesmo padrão de racionalidade dos sistemas educativos baseados na ideia de transformação do real, que ao se colocarem em uma posição de exceção em relação aos problemas que constituem a realidade, não se ocupam em compreendê-la como sendo sua própria constituição. Para Santos (2007, p. 28), esse modo de pensar configura um problema da crítica na atualidade, pois de acordo com ele "a transformação sem compreensão está nos levando a situações de desastre".

Se os nossos interesses estão comprometidos em perseguir uma ética de profundo respeito pelas comunidades e por outras formas de subjetividade, não podemos recusar o convite a uma reflexão fundada na consciência de que somos resultado de um sistema educativo e cultural eurocêntrico, produtor de regimes de legitimação e princípios de civilidade excludentes. Inevitavelmente, somos impelidos ao reconhecimento de que antes de pensar os efeitos do teatro sobre os outros, advogando transformações das quais não temos garantia, seríamos muito mais produtivos ao pensar as condições que moldam as experiências e as formas como elas se inscrevem no campo social. Consiste em uma ação mais voltada para o presente, centrada nas gramáticas que circunscrevem as práticas e na elaboração de gestos capazes de preparar um futuro de justiça social, em que a arte seja vista como um direito 
de todos, entre outras formas simbólicas igualmente inseridas no tecido de uma sociedade capitalista, colonialista e patriarcal.

Portanto seria insuficiente se os impulsos de nossas inquietações ficassem limitados a um simples objetivo de "democratização" cultural, pois simplesmente refletiria uma visão concentrada em reduzir as desigualdades de acesso aos bens simbólicos, compartilhando formas artísticas determinadas por padrões hegemônicos, sem questionar os regimes de autorização discursiva de onde foram originadas. Mais adiante dessa perspectiva, o paradigma de construção de uma democracia cultural parece-nos mais adequado se o compreendermos a partir de uma abrangência propositora da participação dos sujeitos no fazer cultural, reconhecendo a coexistência de múltiplas culturas e representações em nossa sociedade. Neste sentido, falar em democracia cultural exige relações igualitárias de participação, abertura a uma pluralidade de saberes e fazeres, e principalmente a busca de reconhecimento dos dispositivos de poder e saber que invisibilizam os conhecimentos não legitimados pela hegemonia cultural.

Se observarmos, todas as ações citadas como base para uma construção cultural democrática exigem olhares para o presente e para o que somos, na medida em que solicitam novos modos de produção do conhecimento, convergindo em vários aspectos com a necessidade defendida por Santos (2007), de reinvenção da emancipação social a partir do reconhecimento da existência de uma pluralidade de conhecimentos. Em um contexto em que as expectativas de futuro da maior parte da população mundial não são as melhores, "não é simplesmente de um conhecimento novo que necessitamos; o que necessitamos é de um novo modo de produção do conhecimento. Não necessitamos de alternativas, necessitamos de um pensamento alternativo às alternativas" (SANTOS, 2007, p. 20).

Assim sendo, precisamos olhar para as gramáticas das nossas práxis teatrais, principalmente para a forma como compreendem a participação dos sujeitos, examinando os modos em que se inscrevem social e culturalmente. São práticas construídas a partir de gestos de profanação das dinâmicas de exclusão que, inevitavelmente, perpassam a sua própria constituição enquanto prática artística? Que formas de mise em scène ${ }^{3}$ são produzidas e legitimadas? Como são construídos os discursos sobre as práticas? Entre tantas perguntas

3 Expressão de origem francesa referente à encenação, ao posicionamento de uma cena e aos modos como a cena é dirigida e produzida. 
que poderíamos elencar, imagino que essas sejam suficientes para uma percepção de que as formas como discorremos sobre as práticas estão intimamente ligadas com o que elas são e podem vir a ser. Não é a toa que estamos insistindo nessa reflexão, colocando em debate as formas de pensamento que atravessam os nossos discursos, na perspectiva de que muitas de nossas enunciações possuem caráter performativo (AUSTIN, 1990), ou seja, corresponde à execução de ações que podem ser democráticas ou não.

\section{Somos parte da gramática, mas há derivas pelo caminho}

Sabemos que o desenvolvimento de práticas teatrais comunitárias é anterior à constituição do campo acadêmico que estamos denominando teatro em comunidade e que a atenção das instituições para tais práticas, na maior parte das vezes, esteve relacionada ao caráter contra-hegemônico e subversivo de muitas delas. Ocorre que essa captura foi feita por artistas, pesquisadores, professores, psicólogos, entre vários outros profissionais que foram formados no interior do pensamento moderno ocidental, considerado por Santos (2009, p. 23) um pensamento abissal, ou seja, que divide "a realidade social em dois universos distintos: o universo 'deste lado da linha' e o 'universo do outro lado da linha', universalizando princípios de regulação e emancipação social somente a partir de uma suposta "realidade relevante," autocentrada "deste lado da linha". De acordo com ele, o outro lado "desaparece enquanto realidade" e é excluído por ser produzido como inexistente, tornando-se subordinado às concepções de sujeito, critérios de legitimação do conhecimento e incontáveis formas de opressão e dominação típicas das nossas matrizes colonizadoras.

Compondo as bases de modelos críticos que não ser organizam em torno da possibilidade de copresença dos dois lados da linha, o pensamento moderno ocidental, também circunscrito nas práxis educativas, funda sua perspectiva emancipatória na ausência não dialética do outro, ou seja, o excluído não existe nem como outro. Neste contexto, operam os sistemas de manutenção das mais diversas formas de poder e do capitalismo diluído em expressões de colonialismo cultural e social que impedem uma visão global da realidade. Como consequência, "contrai, diminui, subtrai o presente", porque esse modo de racionalidade não 
permite ter uma visão ampla dele, deixando de fora muita realidade e incorrendo no "desperdício da experiência" (SANTOS, 2007, p. 26).

Seria pretencioso dizer que os discursos sobre o teatro em comunidade não padecem dos mesmos problemas e não partilham das mesmas bases do pensamento ocidental, pois isso ignoraria o seu próprio estabelecimento como campo de investigação acadêmica, sua inscrição no âmbito da arte-educação e o envolvimento de uma diversidade de profissionais - formados nessas grelhas de pensamento - que acreditam nas potencialidades dessa forma de fazer teatro. Também é necessário dizer que essas afirmações não negam a existência de muitas práticas que profanam os dispositivos hegemônicos de poder-saber, muito menos deixa de reconhecer a atuação de incontáveis investigadores e artistas empenhados em construir abordagens decolonizadoras.

Ademais, enfatizamos que as nossas problematizações se referem à captação acadêmica e institucional do teatro em comunidades, fundada em epistemologias monoculturais que perpassam desde os discursos salvacionistas do senso comum até grande parte das críticas autodenominadas inclusivas. Neste sentido, torna-se importante uma breve contextualização sobre as origens e as formas de grande parte dos discursos sobre as artes na educação, identificando como implicam o empreendimento das práticas teatrais em comunidade, para posteriormente tentar encontrar derivas onde possamos profanar esses regimes excludentes de legitimação discursiva.

\section{Uma deriva: teatro em comunidade como prática cultural}

Historicamente, os estudos relacionados à educação artística sempre estiveram muito preocupados em buscar evidências para justificar a importância da arte na educação, posicionamento que no Brasil possui íntimas ligações com as lutas em defesa da obrigatoriedade da arte nos currículos escolares e, atualmente, para a sua permanência. Além disso, muitas vezes carregam as bases ideológicas do imperialismo cultural europeu que sustentava uma visão romântica da arte como parte dos ideais de uma concepção particular de completude humana, como se ela agisse independente dos contextos sociais e culturais. Com efeito, configuram abordagens com caráter instrumental e essencialista, atestando o quanto as concepções de "arte pela arte" e argumentos 
centrados nos efeitos das práticas artísticas podem ser "usados por pessoas específicas e para propósitos específicos de maneira que frequentemente sustentam uma hierarquia social específica" (GAZTAMBIDE-FERNANDEZ, 2013, p. 222, tradução nossa).

De modo similar, como descreve Gaztambide-Fernández, a partir do contexto norte-americano, percebemos que não se trata de uma realidade exclusivamente brasileira e muito menos acreditamos que esteja restrita aos dois países - principalmente em tempos de globalização neoliberal. Ele destaca a constante necessidade dos professores em reafirmar os valores da arte para a manutenção de sua presença no currículo e o modo como a estrutura educacional restringe as possibilidades de um pensamento capaz de superar o caráter instrumental e/ou essencialista.

Como o próprio projeto de ensino é sempre direcionado para objetivos específicos, os defensores geralmente têm que demonstrar como as artes podem aprimorar esses objetivos, sejam eles relacionados à realização acadêmica, ao engajamento cívico ou à coesão social. (GAZTAMBIDE-FERNANDEZ, 2013, p. 213, tradução nossa)

Mesmo não fazendo parte das disputas curriculares instaladas no interior da educação escolar, o teatro em comunidades segue as mesmas linhas de defesa que parecem ter se estendido a qualquer âmbito educativo e estabelecido um princípio único de pensamento educacional: isto é, impondo um modelo replicável que requer inputs para legitimar e determinar se uma ação é educativa ou não - mais um dispositivo de manutenção das distinções do pensamento abissal. Persistir no interior desses modelos talvez tenha a ver com o fato de o teatro em comunidade sempre ter sido impelido a afirmar sua importância dentro do próprio campo hegemônico da arte e da educação artística. Por outro lado, também pela necessidade de as organizações e grupos teatrais precisarem defender a destinação de recursos para os projetos artísticos perante instituições financiadoras que operam no interior do mesmo pensamento cultural e educacional hegemônico.

Diante desses contextos e em tempos de aperfeiçoamento das tecnologias de poder do neoliberalismo, sem dúvidas estaremos diante de muitas interpelações sobre resultados e impactos das práticas artísticas no 
desenvolvimento dos sujeitos, principalmente em termos de produtividade. Por isso, não pretendemos que este debate se confunda com o ato de vestir uma camisa de força contentora das nossas defesas em relação ao teatro em comunidade, muito menos diluir as suas particularidades em relação a outras práticas sociais. Pelo contrário, queremos reafirmar essa importância construindo uma defesa em que o potencial das práticas teatrais em comunidade não fique reduzido ao que Gaztambide-Fernandez (2013) chama de "retórica dos efeitos", ou seja, restrito às abordagens de caráter instrumental ou essencialista.

O foco no que as artes fazem automaticamente já condensa o que ela é - sem deixar margens para o que pode vir a ser - e opera nas mesmas lógicas do pensamento abissal que mitiga qualquer possibilidade de questionamento das dinâmicas sociais e culturais envolvidas nas práxis artísticas. Em suma, são concepções baseadas na exigência de "que todas as experiências dignas que envolvem a criatividade simbólica sejam definidas a priori como boas e previsíveis" (GAZTAMBIDE-FERNANDEZ, 2013, p. 214, tradução nossa), sem questionar as concepções que as qualificam e, consequentemente, perceber que isso resulta na exclusão dos que não atendem às expectativas e padrões do que dizem ser "as artes". Queremos impor uma prática ou construí-la através de um intercâmbio profundo com as comunidades?

Se nossa alternativa for a da construção, temos a tarefa de interromper os discursos de caráter instrumental e essencialista, historicamente endereçados para se alinhar a modelos educativos organizados em torno de um perfil ideal de sujeito, de uma forma de pensamento e de um saber-fazer que se pretende universal. Manter as práxis do teatro em comunidades no interior dessa retórica dos efeitos, pautada por um essencialismo que distingue a arte como espaço intrínseco de liberdade, igualdade e autonomia, não permite a compreensão de que nossas práticas são construídas no interior de determinados padrões culturais, tampouco suscita uma percepção de que elas são resultado de interações humanas reais em contextos hierárquicos e de disputa de poder.

Portanto nos distanciemos das defesas de que o teatro em comunidade por si só é uma experiência emancipadora; diferente disso, precisamos considerar que qualquer impacto - positivo ou não - das práticas teatrais depende 
de interações em contextos concretos, envolvendo múltiplos agentes e processos simbólicos. Nesse entendimento, ironicamente falando em termos de produtividade, seríamos mais produtivos performando nossos discursos nas práticas pensando as práxis como gestos performativos. Significa olharmos para as práticas artísticas como processos de produção cultural - assim como outras experiências simbólicas cotidianas -, atentos às circunstâncias em que os significados são negociados e construídos, de modo que seja um terreno em que os sujeitos possam "engajar o material simbólico de suas vidas diárias", recriando as representações de si e do mundo, "sem necessariamente recircular as relações dominantes" (GAZTAMBIDE-FERNANDEZ, 2013, p. 227, tradução nossa). Então, por que teatro em comunidade se ele é somente uma entre várias outras práticas culturais? Talvez porque, em uma cultura marcada por relações de imperialismo e colonialismo, precisamos defender toda e qualquer oportunidade de prática cultural, enquanto territórios de exercício criativo dos modos de ser, estar, pertencer e se reconhecer - ou não - no mundo. Se daí vai surgir algum tipo de resultado social, não podemos garantir, mas devemos nos empenhar em criar condições para que seja um teatro capaz de olhar para o presente de forma ampliada, incluindo muito mais experiências e desconstruindo as linhas abissais que, de acordo com Santos (2009), impossibilitam a emergência da justiça social. Percebe-se, aqui, que substituímos a retórica dos efeitos por uma "retórica da produção cultural", na qual a atenção está mais voltada a "que tipos de relacionamentos evoluem dentro do contexto das trocas simbólicas envolvendo trabalho criativo" (GAZTAMBIDE-FERNANDEZ, 2013, p. 229, tradução nossa).

Em torno dessa concepção, o maior contributo do teatro em comunidades pode estar em suas capacidades de criar um contexto propício para a evolução dessas experiências culturais, centrando o olhar em suas proposições de participação e identificando até onde permite que as "regras do jogo" sejam colocadas em discussão. Trata-se de construir a utopia da democracia cultural a partir dos processos de democratização dos seus próprios territórios, no próprio exercício da busca de uma cultura política e de uma racionalidade - fundamentada na "relação entre o respeito da igualdade e o princípio do reconhecimento da diferença" de cada sujeito (SANTOS, 2007, p. 62). 


\section{Teatro em comunidade na zona de contato}

No encadeamento da retórica da produção cultural, substituímos o discurso do teatro em comunidade como "algo para as pessoas" por um pensamento que compreende as "formas artísticas como algo que as pessoas fazem" (GAZTAMBIDE-FERNANDEZ, 2013, p. 226, tradução nossa). De fato, em termos de cena teatral pensamos sujeitos em performance sujeitos fazendo algo - (des)organizando materialidades no espaço-tempo, dimensão onde se situam as demais experiências da vida. Contrapõe-se, portanto, à ideia de que a visão do teatro em comunidade como prática cultural é um pensamento que se distancia da cena, pois ela emerge nas mesmas dimensões das práticas culturais.

Aliás, se pudéssemos falar sobre alguma característica intrínseca ao teatro, é menos arriscado pensar em termos como tempo, espaço e corpo, variáveis condicionantes de todo acontecimento, de toda experiência simbólica, independente de qualquer prática dita artística. Entendemos, portanto, que a criação teatral resulta do ato de estar em relação com esses elementos condicionantes no exercício da produção simbólica, jogando com as temporalidades, espacialidades e corporeidades, em circunstâncias particulares, constituindo uma presença em forma de cena. Sendo assim, ao estar situada nas mesmas dimensões dos sujeitos que operam sua presença e que também estão presentes em performance, podemos afirmar que a cena é uma produção investida por forças, um "corpo" produzido tal qual são os sujeitos mais um fator para continuarmos no interior da retórica da produção cultural.

Sendo assim, não podemos dar garantias sobre o que o teatro em comunidade faz, mas podemos observar as condições nas quais esse corpo é produzido, já que ele será mais uma presença no mundo e a representação de um poder do qual é agente e depositário. Nesse cenário, entende-se o corpo como a expressão de forças de poder e saber que interviram materialmente, atingindo sua realidade mais concreta - sua própria constituição - e que se situa "ao nível do próprio corpo social, e não acima dele, penetrando na vida cotidiana" (FOUCAULT, 1979, p. XII).

Em síntese, denota-se que a performance teatral é a continuidade dos acontecimentos culturais e sociais que precedem a sua construção, e embora 
não possamos prever os seus efeitos, é preferível que pensemos a cena como um corpo que transporta experiências de existência mais justas. Provavelmente isto é o que mobiliza a nós, artistas, professores, pesquisadores empenhados na construção das práxis do teatro em comunidade - a tentativa de reinventar os nossos modos de ser e estar no mundo, a partir do contato com o outro e das possibilidades de ter coexistências em um mesmo espaço. Mas não é uma tarefa simples, constatados o padrão abissal de pensamento e as racionalidades inscritas em nossa educação, para tanto um modo produtivo e operativo de olhar para o teatro em comunidade, profanando esses modos hegemônicos de enunciação e as abordagens de caráter instrumental, é a perspectiva da zona de contato.

Conforme conceitua Pratt (2010), a zona de contato é um espaço de encontros coloniais onde pessoas de diferentes lugares e contextos histórico-sociais entram em contato e estabelecem relações, geralmente coercitivas e desiguais. Para a autora, essa perspectiva destaca como os sujeitos são constituídos nas e pelas suas relações uns com os outros, pensando a relação entre colonizadores e colonizados "não em termos de separação, mas em termos de presença simultânea" (PRATT, 2010, p. 34, tradução nossa), mesmo em relações assimétricas de poder. Assim, não precisamos negar a inevitabilidade dos nossos poderes-saberes, conferidos inclusive pelos nossos títulos de artistas e/ou professores, mas nos posicionaremos como uma presença comum a qualquer outra, de modo que o resultado dessa interação vai constituir uma fronteira, gerando outra forma de presença que aqui estamos compreendendo como a cena - um corpo resultante das forças que agiram sobre ele e agente desses mesmos poderes.

Certamente a construção das práxis do teatro em comunidade é na zona de contato, nesse espaço em que somos impelidos a assumir a nossa diferença e reconhecer a diferença do outro, revelando a percepção de que somos iguais na diferença e, consequentemente, com o mesmo grau de autoridade no interior da zona de contato. É esse o espaço em que vamos construir as nossas presenças enquanto sujeitos, como agentes e depositários dos sentidos agenciados por todos, mas também o espaço de construção de um corpo gerado entre as nossas "linhas de diferença e hierarquia, ou através delas" (PRATT, 1999, p. 12), que será expressão das nossas relacionalidades na zona de contato. 
Se a construção deste corpo precisou gerar invisibilidades ou aniquilar qualquer possibilidade de presença para além dele, provavelmente não conseguimos adentrar a zona de contato, pois as relações se estabeleceram por linhas abissais, ou seja, não fomos capazes de estar em copresença e desperdiçamos uma diversidade de experiências que poderiam gerar novas formas de ser, fazer e estar em cena - e na vida. Por isso, precisamos assumir radicalmente a responsabilidade de nossas presenças e reconhecer as gramáticas que nos constituem, pois os nossos poderes-saberes são construtores de outros corpos e também erguem muros que impedem a entrada na zona de contato. Teria algum sentido o teatro em comunidade fora da zona de contato?

\section{Referências bibliográficas}

AUSTIN, J. L. Quando dizer é fazer. Tradução de Danilo Marcondes de Souza Filho. Porto Alegre: Artes Médicas, 1990.

FOUCAULT, M. Microfísica do poder. Tradução de Roberto Machado. Rio de Janeiro: Graal, 1979.

GAZTAMBIDE-FERNANDEZ, R. Why the arts don't do anything: toward a new vision for cultural production in education. Harvard Educational Review, Cambridge, MA, v. 83, n. 1, p. 211-236, 2013. DOI: 10.17763/haer.83.1.a78q39699078ju20.

NOGUEIRA, M. P. Teatro e comunidade. In: FLORENTINO, A.; TELLES, N. (org.).

Cartografias do ensino do teatro. Uberlândia: Edufu, 2009. p. 173-184.

NOGUEIRA, M. P. Um olhar sobre o teatro em comunidades no Brasil. In: CRUZ, H.

Arte e comunidade. Porto: Fundação Calouste Gulbenkian, 2015. p. 101-126

PRATT, M. L. A crítica na zona de contato: nação e comunidade fora de foco. T ravessia, Florianópolis, n. 38, p. 7-29, 1999. Disponível em: https://bit.ly/2vB6JtR. Acesso em: 31 mar. 2019.

PRATT, M. L. Ojos imperiales: literatura de viajes y transculturación. Tradução de Ofelia Castillo. Ciudad de México: FCE, 2010.

SANTOS, B. S. Renovar a teoria crítica e reinventar a emancipação social. Tradução de Mouzar Benedito. São Paulo: Boitempo, 2007.

SANTOS, B. S. Para além do pensamento abissal: das linhas globais a uma ecologia de saberes. In: SANTOS, B. S.; MENEZES, M. P. Epistemologias do Sul. Coimbra: Almedina, 2009. p. 23-71.

Recebido em 31/03/2019

Aprovado em 31/10/2019

Publicado em 09/03/2020 